\title{
Incidence of Congenital heart disease among the neonates in neonatal intensive care unit of a tertiary care hospital
}

\author{
Dinakara $P^{1}$, Reddy Bharath $D^{2}$, Rajeshwari $S^{3}$, Renganathen $G^{4}$ \\ ${ }^{1}$ Dr. Dinakara Prithviraj, Associate Professor, ${ }^{2}$ Dr. Bharath Reddy, Assistant Professor, ${ }^{3}$ Dr. Rajeshwari S, Junior \\ Resident, ${ }^{4}$ Dr. Utkarsh Jain, Junior Resident, all authors are affiliated with Department of Pediatrics, Vydehi Institute of \\ Medical Sciences and Research Institute, Bengaluru, Karnataka, India.
}

Address of Correspondence: Dr Dinakara Prithviraj, Associate Professor, Department of Pediatrics, Vydehi Institute of Medical Sciences, Bangalore. drdinakar.nishanth@gmail.com

\begin{abstract}
Background: A large number of newborns are affected by congenital heart diseases, which accounts for a high proportion of infant mortality worldwide. But there are regional variations in the prevalence and distribution pattern of congenital heart diseases. We evaluated the incidence, risk factors and diagnostic clues for congenital heart disease in newborns in our neonatal intensive care unit. Methods: A prospective observational study was conducted in the neonatal intensive care unit of Vydehi institute of medical sciences between January 2013 to December 2016. Congenital heart disease was suspected if clinical and confirmed by 2D echocardiography and doppler and colour flow imaging. Data was collected on a predesigned proforma containing information regarding gender, gestational age and weight at birth, family history, and associated malformations. Results: Out of 1974 babies screened for CHDs, 126 babies had CHDs (4.6\%) of which $71(56 \%)$ were males. Most of neonates presented with Respiratory distress (52.3\%), murmurs (49.5\%), abnormal chest X ray (27.7\%), followed by cyanosis (18.2\%) in Cyanotic CHDs(100\% of the cases). Conclusion: The incidence of CHD in newborns at the neonatal intensive care unit was higher than that in all live births.VSD was the most common congenital heart defect detected while Tetralogy of Fallot was commonest among the cyanotic heart defects.
\end{abstract}

Keywords: Congenital heart disease, screening, Echocardiography

\section{Introduction}

Congenital heart diseases (CHDs) are defined as a gross structural abnormality of heart or intrathoracic great vessels that are of functional significance occurring as an isolated or associated with other congenital anomalies. Twenty-eight percent of all major congenital anomalies are associated with heart defect ${ }^{1}$. The incidence of congenital heart defects in neonates is varied in different studies and is usually reported to be 3-5/1000 live births. Recent studies have reported incidence of CHDs to range between 8 to $10 / 1000$ live births [1].

Congenital heart diseases are the most common congenital fetal malformations and are responsible for a high rate of child mortality and morbidity. In India, Congenital Heart Disease may account for $10 \%$ of the present infant mortality. CHDs are more frequent in

Manuscript received: $2^{\text {nd }}$ April 2017

Reviewed: $11^{\text {th }}$ April 2017

Author Corrected: $18^{\text {th }}$ April 2017

Accepted for Publication: $25^{\text {th }}$ April 2017 neonates in the neonatal intensive care unit than in live born neonates in population. About $25 \%$ of CHDs are life threatening and may manifest before the first routine clinical examination. Failure to identify these critical lesions immediately after birth leads to delay in referral and increased mortality and morbidity [2]. Recent studies have reported a high sensitivity and specificity for pulse oximetry for early detection of CHD in newborn infants. Combining pulse oximetry with clinical examination can enhance the clinician's ability to detect life-threatening CHD in a timely manner. Heart murmur, central cyanosis and major congenital abnormalities were found statistically higher in the neonates with cardiac disorder $[3,4]$.

The incidence and type of CHDs are varied among neonates with normal or low or extremely low birth weight. There are, however, few studies of the incidence in very low birth weight neonates; most studies relate to gestational age rather than birth weight. 
The purpose of this study was to determine the incidence, pattern of CHD like weight, clinical signs, and pulse oximetry diagnosis in neonates in a neonatal intensive care unit of a tertiary care institute [5].

\section{Materials and Methods}

A 5-year prospective observational study was done between January 2012 to December 2016 in the neonatal ICU of Vydehi institute of medical sciences. In this observational study, all the neonates suspected to have congenital heart disease in the NICU on the basis of history clinical examination, pulse oximetry, chest $\mathrm{X}$ ray were included in the study and confirmed by $2 \mathrm{D}$ echocardiography and colour Doppler study. On the basis of echocardiography, profile of various congenital heart defects was studied.

A total of 2658 cases were admitted in neonatal ICU during this study period in which screening ECHO was done in 1974 cases. The same trained neonatologist performed clinical evaluation and ECHO within the first 24 hours of admission to the NICU.

Screening ECHO was done in the below cases[6].

1. Any child with $\mathrm{SpO}_{2}<94 \%$ at room air/or visible cyanosis

2. Respiratory distress

3. Murmur

4. Abnormal heart sounds

5. Abnormal Blood Pressure

6. Differential Peripheral pulses

7. Abnormal chest X-Ray

8. Unexplained CHF

9. Preterm babies with gestation less than 37 weeks or birth weight less than $2500 \mathrm{gms}$

10.Babies born to mothers with gestation diabetes mellitus.
We conducted screening for $\mathrm{SpO}_{2}$ using Masimo $\mathrm{Rad} 7$ pulse oximetry (Masimo Corporation, Irvine, CA, USA) and disposable probes. All patients in our NICU are continuously monitored with a pulse oximetry throughout their stay. The same probe was used sequentially to determine the right upper limb and a lower limb $\mathrm{SpO}_{2}$. Each screening attempt was conducted over a 3-min period with the infant in the supine position. The pulse oximetry measure was considered complete once the waveform on the plethysmograph was stable.

Interatrial septum opening less than $5 \mathrm{~mm}$ and the patent ductus arteriosus (PDA) presenting in first 72 hours is not taken into the study [7, 8]. PDA if found hemodynamically significant, that is having ductal diameter more than $1.4 \mathrm{~mm}$, Pulse-wave Doppler of the descending aorta shows reversed end-diastolic flow, Pulse-wave Doppler in main pulmonary artery shows turbulent systolic and diastolic flow and large left-toright shunt with a pulsatile flow pattern and the highest velocity at end systole are taken into the study group. Neonates less than $500 \mathrm{gms}$, died within 3 days of life or admission to NICU were excluded from the study.

Sociodemographic characteristics, perinatal characterristics, maternal history, physical examination, echocardiography results were recorded. Maternal age, miscarriage and stillbirth, brother history of CHD, diabetes, systemic lupus erythematosis (SLE), exposure to radiation, TORCH infection in pregnancy, smoking and alcohol use, intermarriage, CHD in the family were included. A trained neonatologist using Hd11XE performed ECHO -Philips using mainly Cardiac probes $12-14$, if any abnormality detected was confirmed by a qualified cardiologist and followed upto 6 weeks.

Statistical analysis: The demographic features, incidence of echocardiographic evaluation in the preand post CHD screening epochs and among preterm and term infants were analyzed by unpaired ' $t$ ' test or $\chi^{2}$ test as appropriate. Significance was accepted at $\mathrm{P}<0.01$

\section{Results}

Total of 2658 cases were admitted in the NICU during the study period of which 1974 cases were screened for CHDs. Out of 1974 babies 126 babies had CHDs (4.6\%), of which 71(56\%) were males. Acyanotic heart defects contributed to 95(75.30\%) cases while cyanotic heart defects contributed 31(24.70\%) cases. Prevalence of CHD was found to be 4.60/1000 live births during the study period. Non-cyanotic CHD was observed in 95(75\%) patients and cyanotic CHD was in 20.VSD was the most common lesion. Profile of various CHDs was VSD 41(32.5\%), ASD 22(17.4\%), PDA 32(25.3\%), TOF 07(5.5\%), Single Ventricle 01(0.7\%), TAPVC 07(5.5\%), PS 02(1.5\%), TGA 02(1.5\%) and Tricuspid Atresia 01(0.7\%). (Table 1) 
In the subgroup of babies with gestation less than 37 weeks, 86(68\%) had CHDs compared to that term babies. Based on the weight 21(16\%) babies above 2500 gms had CHDs whereas $42(33.3 \%)$ babies less than 1000gms and 63 (50\%) had CHDs between weight group of 1500 to 2500gms. (Table2). Most of neonates presented with Respiratory distress (52.3\%), murmurs $(49.5 \%)$, abnormal chest $\mathrm{X}$ ray $(27.7 \%)$, followed by cyanosis $(18.2 \%)$ in Cyanotic CHDs (100\% of the cases) (Table 3)

Table-1: Spectrum of CHDs in NICU.

\begin{tabular}{|c|c|c|c|}
\hline Diagnosis & $\begin{array}{l}\text { Male } \\
\text { n (\%) }\end{array}$ & $\begin{array}{c}\text { Female } \\
\text { n (\%) }\end{array}$ & $\begin{array}{l}\text { Total } \\
\text { n }(\%)\end{array}$ \\
\hline Ventricular Septal Defect (VSD) & 25 & 16 & $41(32.5 \%)$ \\
\hline Atrial Septal Defect (ASD) & 13 & 9 & $22(17.4 \%)$ \\
\hline Patent Ductus & 19 & 13 & $32(25.3 \%)$ \\
\hline 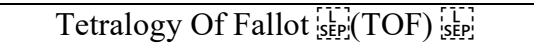 & 3 & 4 & $07(5.5 \%)$ \\
\hline Single Ventricle & 0 & 1 & $01(0.7 \%)$ \\
\hline $\begin{array}{c}\text { Total Anomalous îL Pulmonary Venous } \\
\text { Connection (TAPVC) }\end{array}$ & 4 & 3 & $07(5.5 \%)$ \\
\hline Pulmonary Stenosis (PS) & 2 & 0 & $02(1.5 \%)$ \\
\hline Tricuspid Atresia (TA) & 0 & 1 & $01(0.7 \%)$ \\
\hline 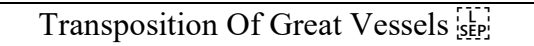 & 1 & 1 & $02(1.5 \%)$ \\
\hline Others & 4 & 7 & $11(8.7 \%)$ \\
\hline Total & 71 & 55 & 126 \\
\hline
\end{tabular}

Table-2: Distribution of CHDs by birth weight and gestation.

\begin{tabular}{|c|c|c|c|c|}
\hline Gestation age & $\begin{array}{c}\text { Number of children } \\
\text { (No. Per 1000/live } \\
\text { births) }\end{array}$ & $\begin{array}{c}\text { >2500gms } \\
\mathbf{n = 2 5 7}\end{array}$ & $\begin{array}{c}\text { 1500-2500gms } \\
\mathbf{n = 1 0 7 9}\end{array}$ & $\begin{array}{c}<\mathbf{1 5 0 0 g m s} \\
\mathbf{n}=\mathbf{6 3 8}\end{array}$ \\
\cline { 3 - 5 } & 86 & - & 44 & 42 \\
\hline $\begin{array}{c}<7 \text { weeks } \\
(\mathrm{n}=1123)\end{array}$ & 40 & 21 & 19 & - \\
\hline $\begin{array}{c}>37 \text { weeks } \\
(\mathrm{n}=851)\end{array}$ & $\mathbf{1 2 6}$ & $\mathbf{2 1}$ & $\mathbf{6 3}$ & $\mathbf{4 2}$ \\
\hline Total & &
\end{tabular}

Table-3: Symptomatology of CHDs.

\begin{tabular}{|c|c|c|c|}
\hline Symptoms & $\begin{array}{c}\text { ACHDs(N=95) } \\
\mathbf{n}(\mathbf{\%})\end{array}$ & $\begin{array}{c}\text { CCHDs(N=20) } \\
\mathbf{n}(\mathbf{\%})\end{array}$ & $\begin{array}{c}\text { Total(N=126) } \\
\mathbf{n}(\mathbf{\%})\end{array}$ \\
\hline Murmur & $48(50.4 \%)$ & $14(70 \%)$ & $62(49.5 \%)$ \\
\hline Cyanosis & 00 & $20(100 \%)$ & $23(18.2 \%)$ \\
\hline Respiratory distress & $54(56.8 \%)$ & $12(60 \%)$ & $66(52.3 \%)$ \\
\hline CHF & $38(40 \%)$ & $6(30 \%)$ & $44(34.9 \%)$ \\
\hline Abnormal Chest X ray & $21(22.1 \%)$ & $14(70 \%)$ & $35(27.7 \%)$ \\
\hline
\end{tabular}

\section{Discussion}

Acyanotic defects contributed $75.3 \%$ while cyanotic contributed $24.7 \%$ of the total case diagnosed. The prevalence of CHDs is 4.6 / 1000 live birth in Neonatal ICU. It was more than the study done by Khalil who found prevalence to be 3.9/1000 live births. But the study done by Hussain in 2014 found even higher prevalence of 15/1000 live births. Shima et al suggested that the occurrence rate of CHD was approximately $4.5 \%$ of neonates admitted to the neonatal intensive care unit[9]. Higher frequency of emergence of CHD is an expected result, because of being sick babies, inspection of every day and more frequent evaluation of echocardiography in this group. In a study that performed on 3334 neonates in neonatal intensive care unit, the frequency was found to be $4 \%$. 
In our study CHDs in preterm was around $68 \%$ and $83 \%$ in low birth weight babies. Archer et al. reported that CHD is probably more frequent in very low birth infants treated in neonatal intensive care units than in the general live-born population [10].

In our study, VSD constituted upto $31.5 \%$ CHDs while the study done by Khalil, Islam and Hussain showed higher prevalence of VSD as follows 34.8\%, 29\% and $31.3 \%$. According to Aydogdu et al and Shima et al the most common cyanotic congenital heart disease was tetralogy of Fallot and the most common Acyanotic heart disease was VSD in the neonatal intensive care unit. In our study results were same with those published reports $[11,12]$.

\section{Conclusion}

In conclusion, the incidence of CHD in newborns at the neonatal intensive care unit was higher than that in all live births. Its incidence varies from center to center due to different factors like sample size, nature of the sample, method of detection and early examination by a neonatologist. In this study a higher incidence is reported because it was carried out in a tertiary care unit and prematurity prevalence was higher. The most frequent diagnostic clue was cardiac murmur and respiratory distress. VSD was the most common congenital heart defect detected while Tetralogy of Fallot was commonest among the cyanotic heart defects. Majority of the acyanotic heart defects were asymptomatic but detected on auscultation and had cyanosis and fast breathing as their presentation.

Funding: Nil, Conflict of interest: None initiated, Perission from IRB: Yes

\section{References}

1. Yu Z, Xi Y, Ding W, Han S, Cao L, Zhu C, Wang X, Guo X. Congenital heart disease in a Chinese hospital: pre- and postnatal detection, incidence, clinical characteristics and outcomes. Pediatr Int. 2011 Dec; 53 (6): 1059-65. doi: 10.1111/j.1442-200X.2011. 03450.x. Epub 2011 Oct 30.

2. Reich JD, Miller S, Brogdon B, Casatelli J, Gompf TC, Huhta JC, Sullivan K. The use of pulse oximetry to detect congenital heart disease. J Pediatr. 2003 Mar; 142 (3): 268-72.

3. Hoffman JI. Congenital heart disease: incidence and inheritance. Pediatr Clin North Am. 1990Feb;37(1): 25-43.

4. Gupta A, Abqari S, Shahab T, Rabbani MU, Ali SM, Firdaus U. Profile and Clinical Spectrum of Congenital Heart Defects in NICU. Int Arch BioMed Clin Res. 2016 April; 2(2):25-27.

5. Saxena A. Congenital heart disease in India: a status report. Indian J Pediatr. 2005 Jul;72(7):595-8.

6. Wren C, Richmond S, Donaldson L. Presentation of congenital heart disease in infancy: implications for routine examination. Arch Dis Child Fetal Neonatal Ed.1999; 80:49-53.

7. Bakr AF, Habib HS. Combining pulse oximetry and clinical examination in screening for congenital heart disease. Pediatr Cardiol. 2005 Nov-Dec;26(6):832-5.

8. Islam MN, Hossain MA, Khaleque MA, Das MK, Khan MRH, Bari MS, Bhuiyan MKJ. Prevalence of Congenital Heart Disease in Neonate in a Tertiary Level Hospital. Nepal Journal of Medical sciences 2013; 2(2):91-5.

9. Hussain S, Sabir MU, Afzal M, Asghar I. Incidence of congenital heart disease among neonates in a neonatal unit of a tertiary carehospital. J Pak Med Assoc 2014; 64: 175-178.

10. Ufuk Kursat Korkmaz, Esra Akyuz Ozkan, Ayse Neslin Akkoca, Ebru Sivaslioglu. Incidence and Clinical Characteristics of Congenital Heart Disease among Neonates in Neonatal Intensive Care Unit. American Journal of Health Research. Vol. 3, No. 3, 2015, pp. 161-165.

11. Shima Y, Takechi N, Ogawa S, Fukazawa R, Fukumi D, Uchikoba Y, et al. Clinical characteristics of congenital heart disease diagnosed during neonatal period. J Nihon Med Sch 2001; 68: 510-515.

12. Khalil A, Aggarwal R, Thirupuram S, Arora R. Incidence of congenital heart disease among hospital live births in India. Indian Pediatr. 1994 May;31 (5): 519-27.

\section{How to cite this article?}

Dinakara P, Reddy Bharath D, Rajeshwari S, Renganathen G. Incidence of Congenital heart disease among the neonates in neonatal intensive care unit of a tertiary care hospital. J PediatrRes.2017;4(04):253-256.doi:10.17511/ijpr.2017.i04.02. 